\title{
إثبات صفة العلو بين السلف والخلف
}

\section{محمد محمود علي شحاتة}

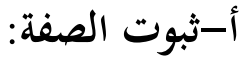

العلو يأتي على ثلاث معان: - (2)

1-علو القهر والغلبة.

2- 2 - 2 - 2 - 2لو الرتبة والمنزلة.

3-علو الذات، والفوقية الحسية على جميع المخلوقات.

ولا نزاع في المرتبتين الأوليين، وإنما النزاع في الثالثة، وهي محل البحث. وقد ورد العلو الذاتي في نصوص كثيرة من القرآن والسنة، منها:

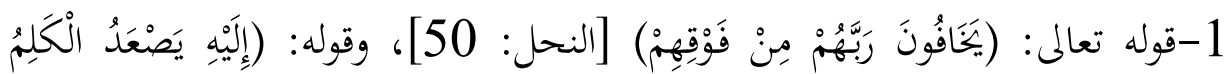

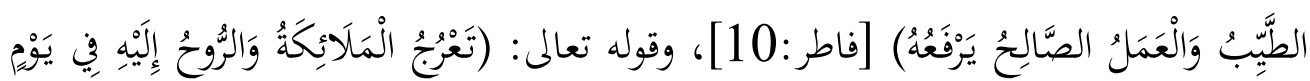

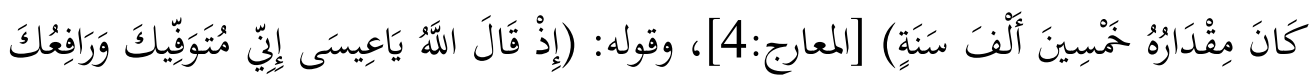

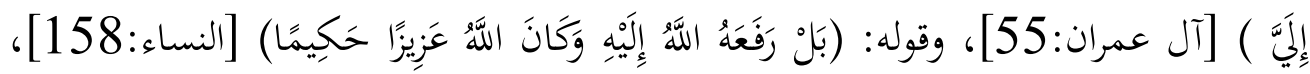

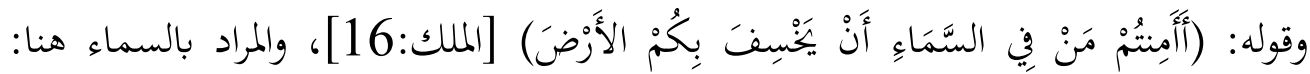

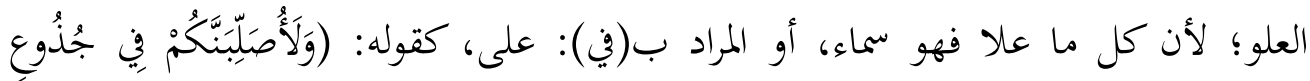
النَّخْلِ) [طه: 71]]، فإِن حروف الجر ينوب بعضها عن بعض (1).

ولا يقول أحد من السلف إن الله مصور أو داخل في هذه السموات المبنية. قال البيهقي في الاعتقاد، ص107: "باب القول في الاستواء قال الله تبارك وتعالى: (الرحمن على العرش استوى)، والعرش هو السرير المشهور فيما بين العقلاء ... وقال: (أمنتم من في السماء)، وأراد من فوق السماء، كما قال: (ولأصلبنكم في جذوع النخل)، يعني 


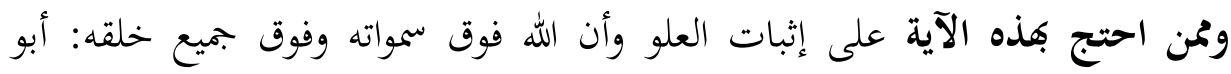

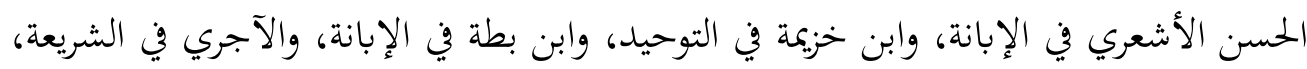

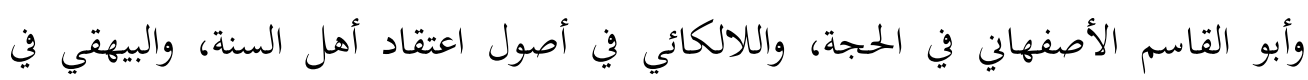
الاعتقاد، وابن قدامة في إثبات صفة العلو، والذهبي في العلو، وغيرهم (1).

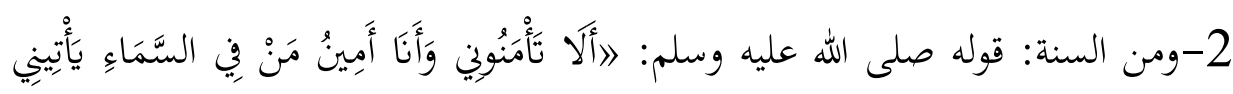

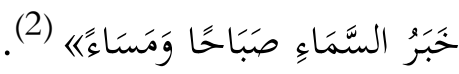

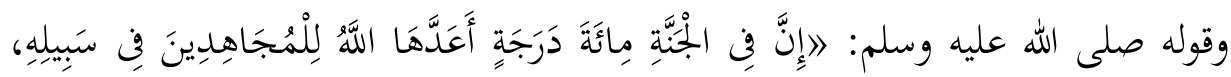

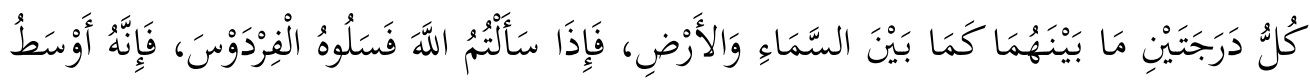

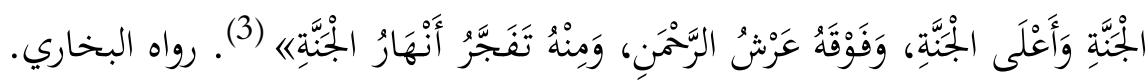

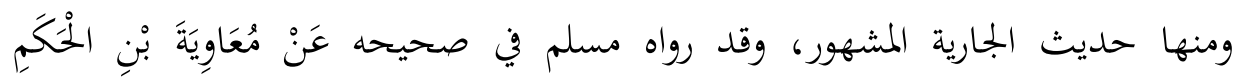

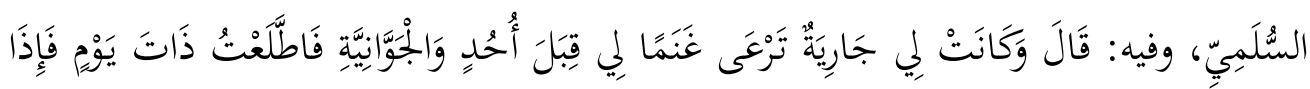

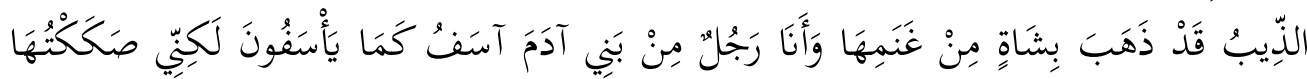

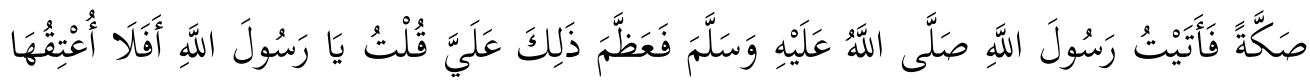

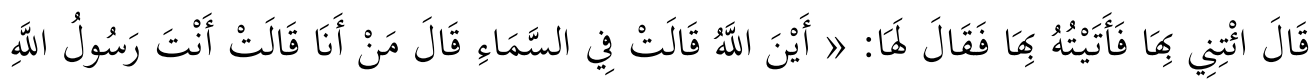

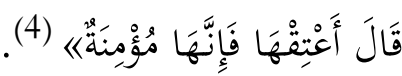
وهذا الحديث احتج به جمع من الأئمة على إثبات العلو لله تعالى، منهم: أبو حنيفة،

على جذوع النخل، وقال: (فسيحوا في الأرض)، يعني على الأرض، وكل ما علا فهو سماء، والعرش أعلى السماوات،

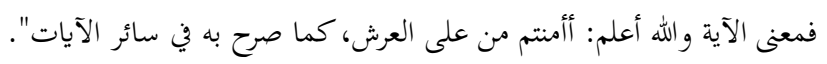

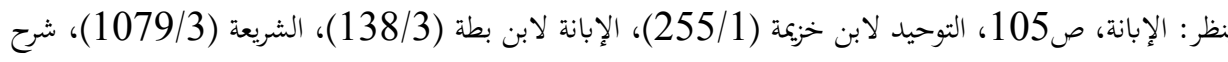

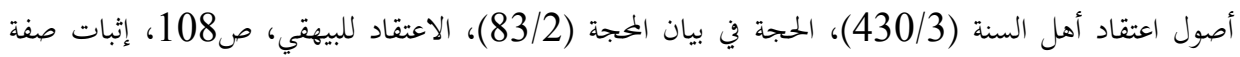

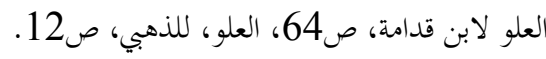

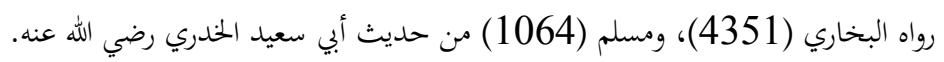

$$
\begin{aligned}
& \text { رواه البخاري (7423). } \\
& \text { رواه مسلم (537)، والحديث رواه مالك (1423) (1468)، وأمد (23762)، أبو داود (930). }
\end{aligned}
$$


والشافعي، وأبو الحسن الأشعري، وابن خزيمة، وأبو القاسم الأصفهاني، وابن عبد البر، واللالكائي، وابن قدامة، والذهبي (1).

وقدم له الذهبي بقوله: "فمن الأحاديث المتواترة الواردة في العلو".

وساق الحديث ثث قال: "هذا حديث صحيح رواه جماعة من الثقات عن يهيى بن أبي كثير، عن هلال بن أبي ميمونة، عن عطاء بن يسار، عن معاوية السلمي، أخرجه مسلم،

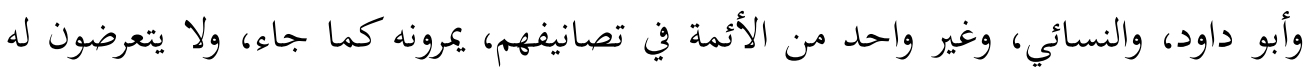
بتأويل ولا تحريف".

ثم قال: "وهكذا رأينا كل من يُسأل أين الله؟ يبادر بفطرته ويقول: في السماء.

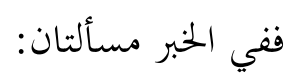

إحداهما: شرعية قول المسلم: أين الله؟

وثانيهما: قول المسؤول في السماء، فمن أنكر هاتين المسألتين فإنما ينكر على المصطفى

صلى الله عليه و سلم" (2).

\section{ب-موقف السلف من صفة العلو:}

أجمع السلف على إثبات هذه الصفة على حقيقتها، وصرحوا بأن الله تعالى فوق سمواته، فوق جميع خلقه، بائنُ منهم، واستدلوا لذلك بما قدمنا من الأدلة وغيرها. وقد حكى إجماعهم جماعة من الأئمة: 1- قال الإمام الأوزاعي رحمه الله (ت:157هـ): "كنا والتابعون متوافرون نقول: إن الله

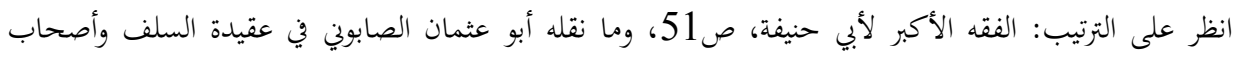

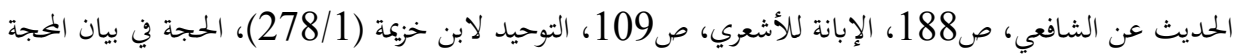

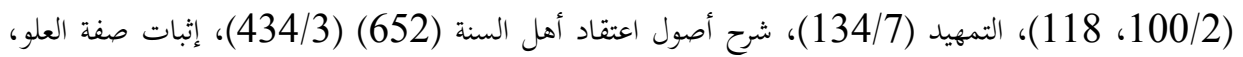
69، العلو للذهبي، ص14. 1180. التهيد العلو، للذهبي، ص28 العلو للني، ص. 
عز وجل فوق عرشه، ونؤمن بما وردت به السنة من صفاته" (1). 2- وقال الإمام إسماعيل بن يجيى المزني رحمه الله (ت264هـ): "الحمد لله أحق من

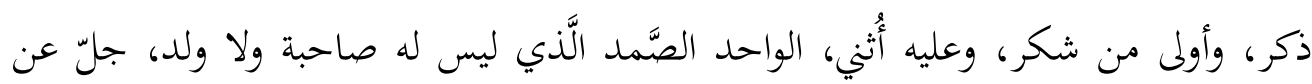

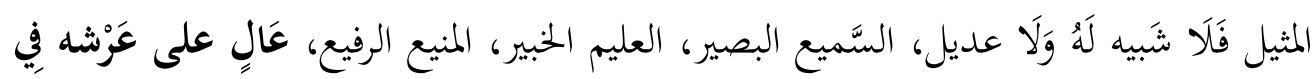

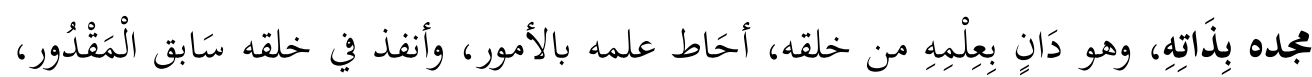

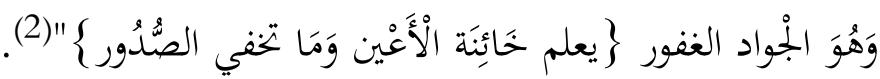

وقال رحمه الله: "عَالِ على عرشه بَائنِّ من خلقه، مَوْجُود وليس بمعدوم ولا بمفقود" (3).

وذكر أن هذه العقيدة مجمع عليها، فقال: "هَذِهِ مقالات وأفعال الجْتمع عَلَيْهَا الماضون

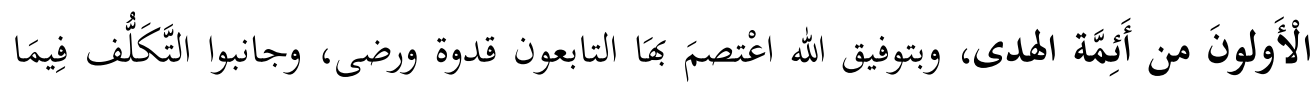

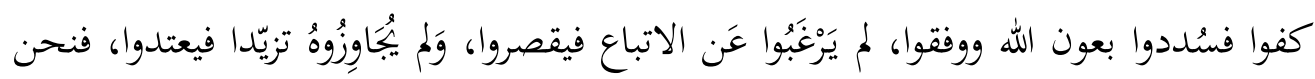
بالله واثقون، وعليه متوكلون، وإليه في اتباع آثَارهم راغبون" (4). 3- وقال الإمام أبو زرعة الرازي (ت:264هـ) والإمام أبو حاتم الرازي (ت: 277هـ) فيما رواه عنهما ابن أبى حاتم رحمه الله، قال: سألت أبي وأبا زرعة عن مذاهب أهل أهل السنة في أصول الدين، وما أدركا عليه العلماء في جميع الأمصار وما يعتقدان في ذلك إنه فقالا: أدركنا العلماء في جميع الأمصار حجازا وعراقا وشاما ويمنا فكان مذهبهم: الإيمان

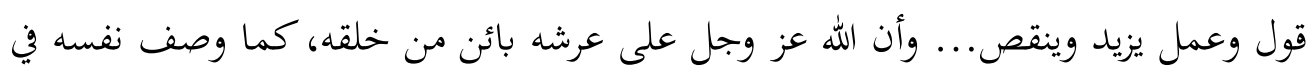

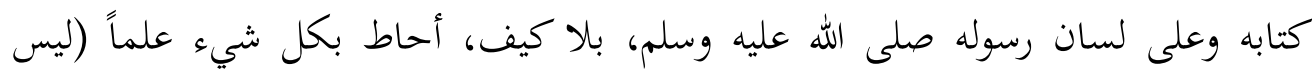

رواه البيهقي في الأسماء والصفات (304/2)، وصححه ابن القيم في اجتماع الجيوش، ص69، وجوّد الحافظ إسناده

$$
\begin{aligned}
& \text { في الفتح (406/13). } \\
& \text { شرح السنة، للمزني، ص75، ت: جمال عزون، ط. مكتبة الغرباء الأثرية. } \\
& \text { السابق، ص80 (30 }
\end{aligned}
$$

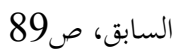




\section{كمثله شيء وهو السميع البصير)" (1).}

4- وقال شيخ الإسلام أبو عثمان الصابوني (372هـ-449هـ): "ويعتقد أصحاب

الحديث ويشهدون أن الله فوق سبع سمواته، على عرشه مستوٍ كما نطق به كتابه ... وعلماء الأمة وأعيان الأئمة من السلف رحمهم الله لم يختلفوا في أن الله على عرشه، وعرشه فوق سمواته"

5- وقال الإمام أبو نصر السجزي (ت: 444هـ) (3) في كتابه الإبانة: "فأئمتنا كسفيان الثوري ومالك وسفيان بن عيينة وحماد بن سلمة وحماد بن زيد وعبد الله بن المبارك وفضيل بن

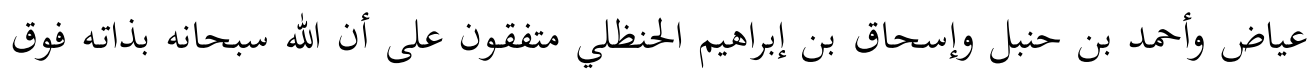

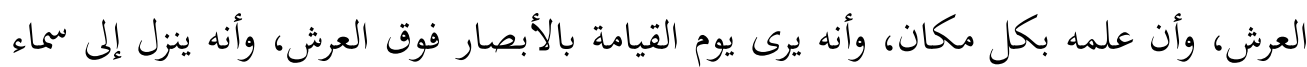

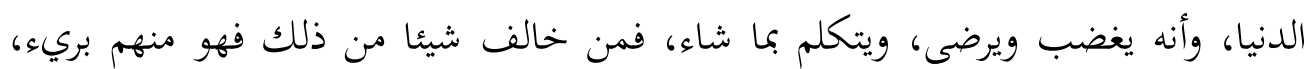

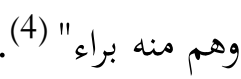

6-وقال الإمام ابن عبد البر (ت:463هـ) بعد ذكر حديث النزول :"وفيه دليل على أن الله عز وجل في السماء على العرش من فوق سبع سموات كما قالت الجماعة، وهو من حجتهم على المعتزلة والجهمية في قولم: إن الله عز وجل في كل مكان وليس على على العرش" (5).

$$
\begin{aligned}
& \text { 1و رواه اللالكائي في شرح أصول اعتقاد أهل السنة والجماعة (201/1-197). }
\end{aligned}
$$

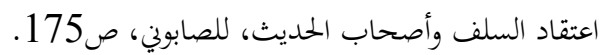

هو عبيد الله بن سعيد بن حاتم الوائلي البكري، أبو نصر السجزي، نسبة إلى سجستان، على غير المانير القياس. الإمام

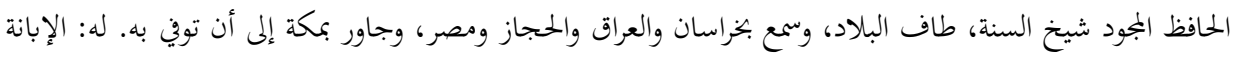

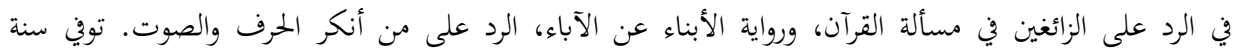

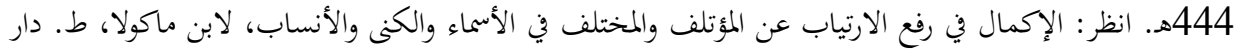

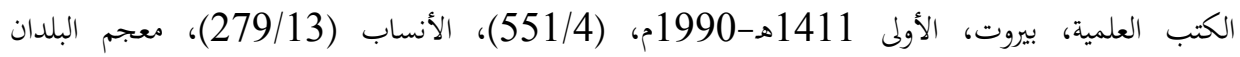

$$
\text { (356/5)، السير (654/17). }
$$

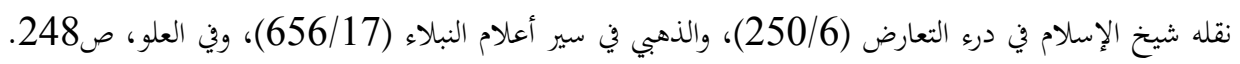

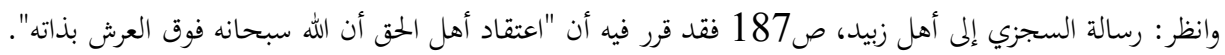

$$
\text { التمهيد (129/7). }
$$


وتثمة إجماعات كثيرة، يرجع إليها في مظاها(1).

وقد احتج جماعة من الأئمة على إثبات العلو بالفطرة، وهي توجه من يدعو الله إلى

جهة الفوق.

ومن استدل بذلك: أبو حنيفة، والأشعري، وابن أبي شيبة، وابن عبد البر، وابن

قدامة(2).

قال ابن عبد البر رحمه الله: "ومن الحجة أيضاً في أنه عز وجل فوق السموات السبع: أن

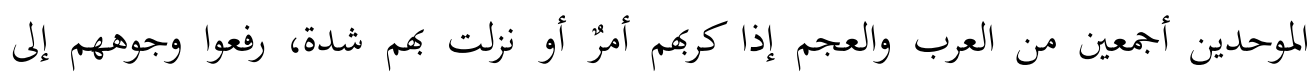

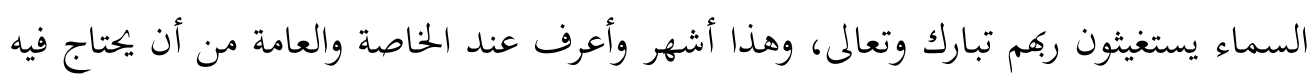

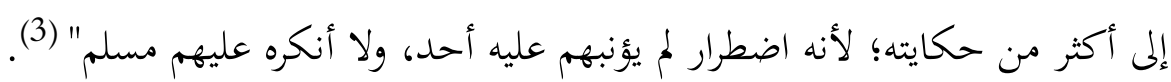

وظاهرٌ من حكاية أقوال السلف في هذه المسألة أفم يثبتون علواً حسياً أو مكانياً

يقررون فيه أن الله فوق العالم، أو فوق العرش الذي على السموات، وقد أكد هذا بعضُهم

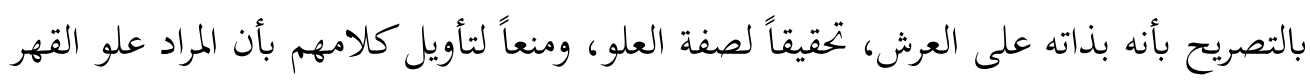

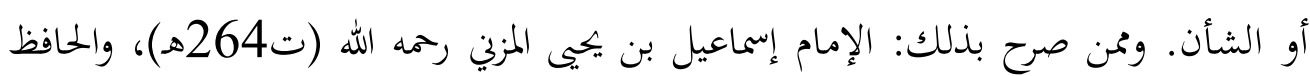

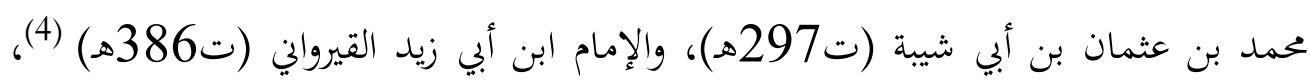

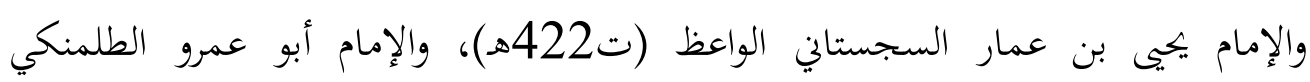

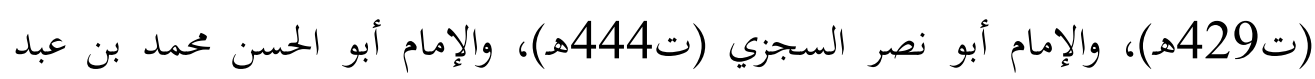

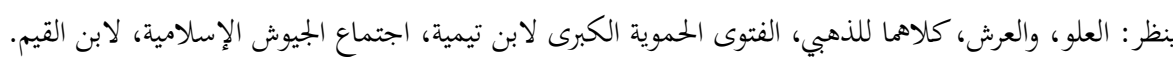

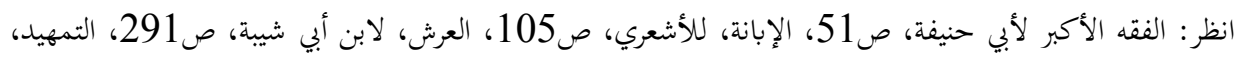

$$
\begin{aligned}
& \text { لابن عبد البر (134/7)، إنبات صفة العلو، لابن قدامة، ص63. } \\
& \text { التمهيد (134/7). }
\end{aligned}
$$

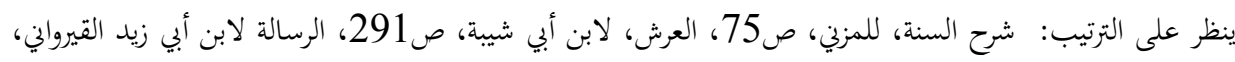

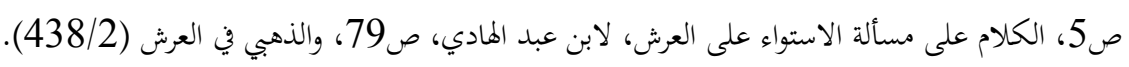


الملك الكرجي الشافعي (ت532هـ)، والإمام عبد القادر الجيلاني (ت 561هـ) (1). كما صرحوا بأنه تعالى بائن من الخلق، وأنه ليس في الأرض أو في كل مكان كما تقول الجهمية، ومنهم من استدل للعلو والبينونة بالعقل، في بيانٍ صريح أن الله خارج العالم. قال الإمام أحمد رحمه الله: " إذا أردت أن تعلم أن الجهمي كاذب على الله حين زعم أن

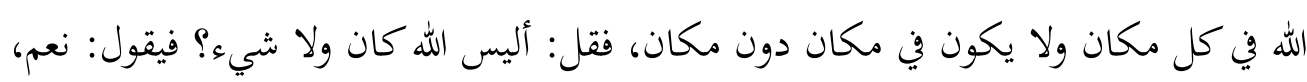

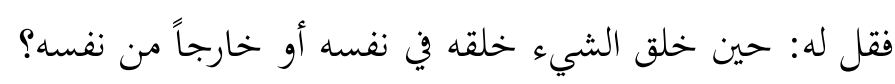
فإنه يصير إلى ثلاثة أقوال لا بد له من واحد منها: إن زعم أن الله خلق الخلق في نفسه، كفر حين زعم أن الجن والإنس والشياطين في نفسه. وإن قال: خلقهم خارجاً من نفسه ثم دخل فيهم، كان هذا كفراً أيضاً؛ حين زعم أنه دخل في مكان وحش قذر رديء.

وإن قال: خلقهم خارجاً من نفسه ثم لم يدخل فيهم، رجع عن قوله أجمع، وهو قول

أهل السنة) (2) (2)

\section{ج-موقف الخلف من صفة العلو:}

ذهب كثير من المتكلمين إلى إنكار العلو الذاتي، والزعم بأنه يستلزم التحيز والجسمية، ثم افترقوا على قولين: - إن

الأول: قول من يقول: إن الله بذاته في كل مكان، وهذا قول الجهمية.

والثاني: قول من يقول: إن الله لا داخل العالم ولا خارجه، ولا متصلاً به، ولا منفصلاً عنه، وهذا قول متأخري الأشعرية.

بنظر: الغنية، لعبد القادر الجيلاني، ص86، العرش، للذهبي (438/2)، والعلو، له، ص235، العادي، الكلام على مسألة

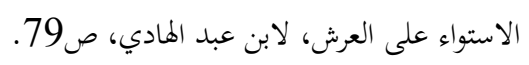

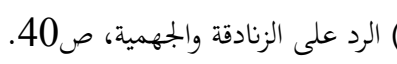


قال الشهرستاني: "فإنا نقول: ليس بداخل العالم ولا خارج؛ لأن الدخول والخروج من

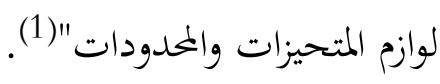

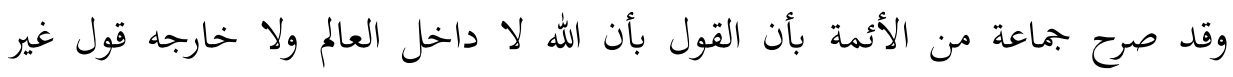

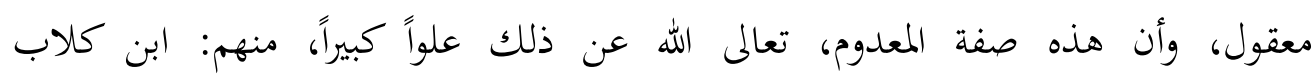
(ت240هـ)، وعبد العزيز الكناني (ت229هـ)، والذهبي، والشوكاني (2). وقد تقدم أن الأشعري وقدماء أصحابه على إثبات العلو. وقد تأول المتأخرون نصوص العلو بتأويلات عدة.

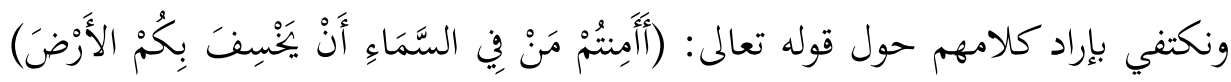
[الملك:16]، ، ، وحول حديث الجارية.

قال الرازي رمه الله في تفسير الآية: "واعلم أن المشبهة احتجوا على إثبات المكان لله تعالى بقوله: (أمنتم من في السماء)، والجواب عنه أن هذه الآية لا يمكن إجراؤها على ظاهرها

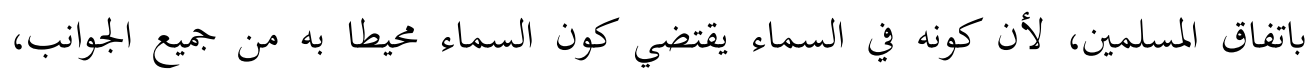

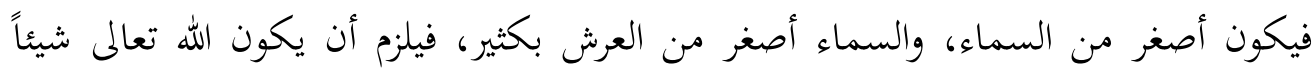

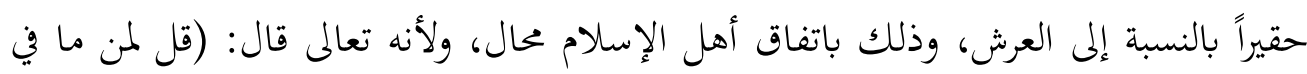

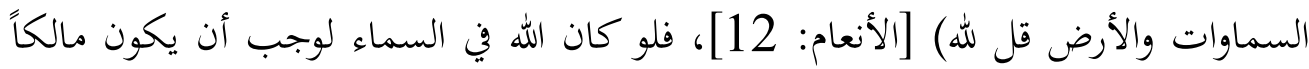
لنفسه وهذا محال، فعلمنا أن هذه الآية يجب صرفها عن ظاهرها إلى التأويل" (3). وقد تقدم ذكر من استدل بالآية على إثبات العلو من السلف والأئمة، لا من المشبهة كما يقول الرازي. ثم هو رمه الله قد بنى استحالة الأخذ بظاهر على ما فهمه من من أنس أن ظاهرها

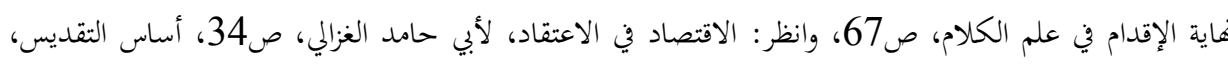

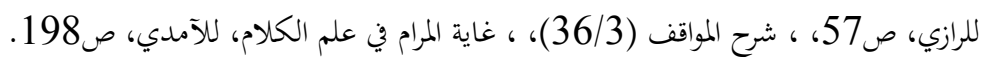

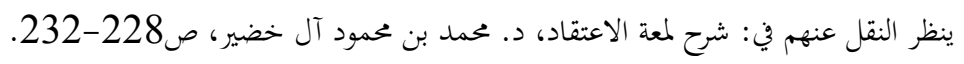


أن الله محصور في السماء، وقد تقدم النقل عن البيهقي-ومثله لأبي الحسن الأشعري- أن

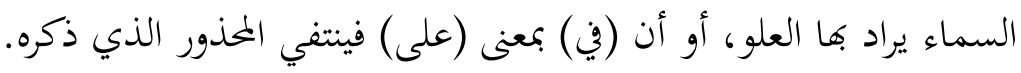
وأما تأويل الآية، فقد ذكر فيه وجوهاً حاصلها: 1-ألمنتم من في السماء عذابه، وذلك لأن عادة الله تعالى جارية، بأنه إنما ينزل البلاء على من يكفر بالله ويعصيه من السماء فالسماء موضع عذابه تعالى. 2-أن العرب كانوا مقرين بوجود الإله، لكنهم كانوا يعتقدون أنه في السماء على وفق

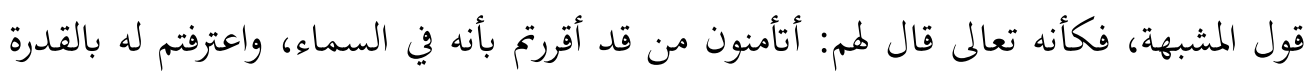

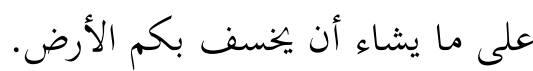
3-أكنتم من في السماء سلطانه وملكه وقدرته، والغرض من ذكر السماء تفخيم

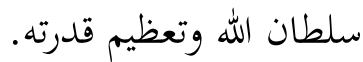
4-أكنتم من في السماء الملكك الموكل بالعذاب، وهو جبريل عليه السلام، والمعنى أن يخسف كمم الأرض بأمر الله وإذنه (1). وأما حديث الجارية، فقد قال الجويني: "فإن قال قائل: فما وجه كلامكم في قوله صلى الله عليه وسلم لها: أين الله؟ قلنا: في ذلك وجهان، أحدها: أنه صلى الله عليه وسلم كلمها على ما قدَّرها عليه، وحسبها معتقدة له، كما روي أنه صلى الله عليه وسلم قال لأم جميل: كم تعبدين من إله اله كاله قالت: خمسة. وإنما يسأل عما يتوقع تعدده، ولا يجوز حمل كلام رسول الهام الله صلى الله عليه

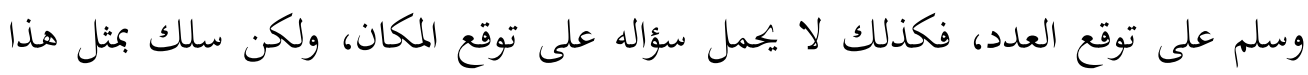
الكلام مسلكَ الاستنطاق بالحق والاستكشاف عن المعتقد، وهذا نخو قوله تعالى: (أين

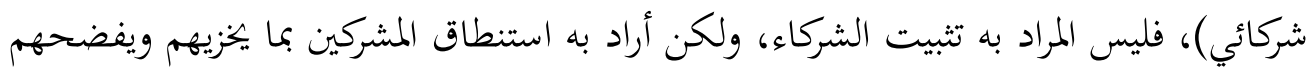


على الملأ العظيم" (1). (1) - (1)

وهذا تأويل عجيب، فلئن سلَّمنا أنه خاطبها بحسب ظنه فيها، واستنطقها ليقف على

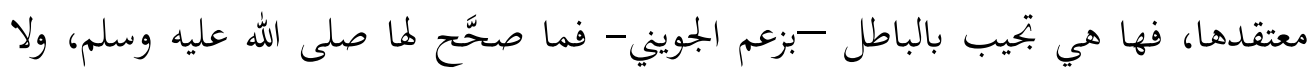
أنكر ولا بيّن، بل كافأها بالعتق!

وأضاف بعضهم وجهين آخرين في تأويل الحديث:

الأول: "أن المهم في صدر البعثة بالنسبة إلى العامة إنا كان إثبات وجود الباري تعالى

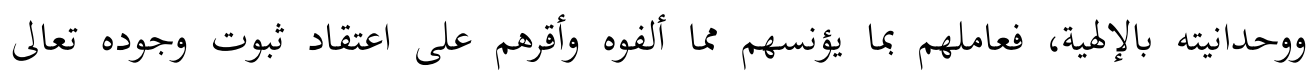

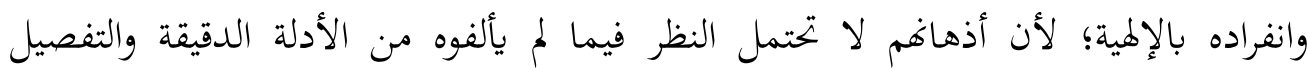
الكلي، فيقع منهم أولا بالإثبات الجملي في ذلك، ولا طريق له إلا بما ألفوه مما تقبله أذهاهم، فلما أشارت إلى السماء علم النبي صلى الله عليه وسلم عظمة الله تعالى عندها ووحدانيته ونفرتا من آلهة الأرض عندها التي كانوا يعبدوها، فلما فهم ذلك منها سأها عن نفسه الكريمة ليعلم إقرارها بنبوته التي هي ثانية عقد الإسلام، فلما قالت: رسول الله، علم إسلامها" (2). وهذا موافق لما قدمناه عن الغزالي والرازي والتفتازاني من أن الشريعة جاءت بالتشبيه، ولم تصرح بالتنزيه لئلا يكفر أكثر الناس، وقد تقدم بطلاه لعربي وتران ذلك.

الثاني: "يجوز أن يراد ب (أين): المنزلة والرتبة في صدرها، كما يقال: أين فلان من فلان،

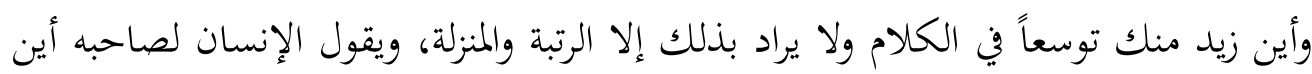

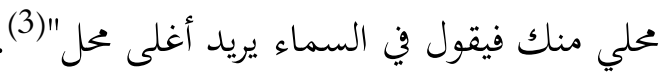

وهذا تكلّف مخالف للظاهر، فلم يكن السؤال عن منزلة الله في صدرها، كما هو بين. ومن المتكلمين من أعرض عن تأويل هذا الحديث، واكتفى برده لأنه حديث آحاد، كما

\begin{tabular}{|c|}
\hline (1) الشامل، للجويني، ص568. \\
\hline 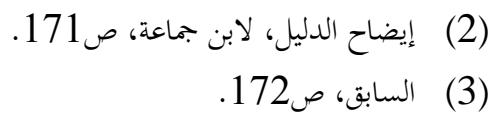 \\
\hline
\end{tabular}


فعل الرازي، لكنه أضاف إلى ذلك الطعن في الصحيحين والزعم أن فيهما أحاديث من وضع

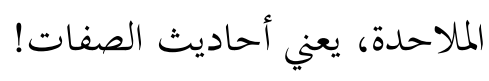

قال الرازي: "الثالث: وهو أنه اشتهر فيما بين الأمة أن جماعة من الماحدة وضعوا أخباراً

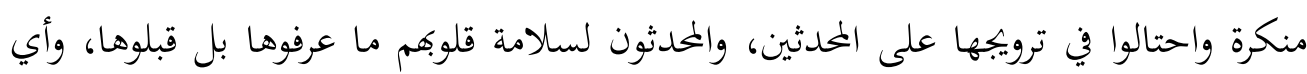

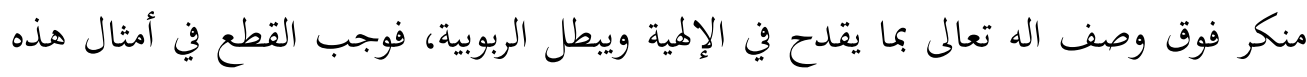

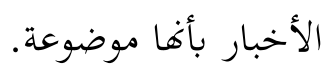

وأما البخاري والقشيري فهما ما كانا عالمين بالغيوب، بل اجتهدا واحتاطا بمقدار

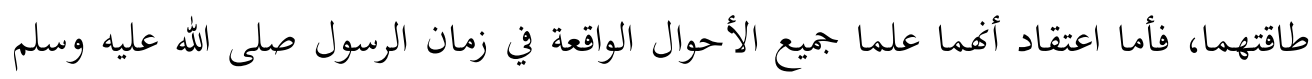

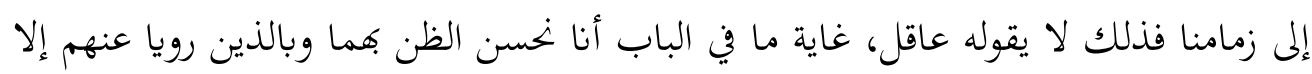

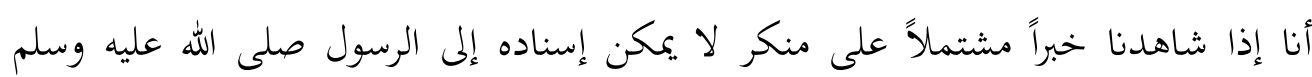
قطعنا بأنه من أوضاع الملاحدة، ومن ترويجاتم على أولئك المالك الخداثين.

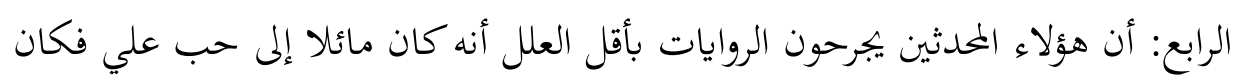

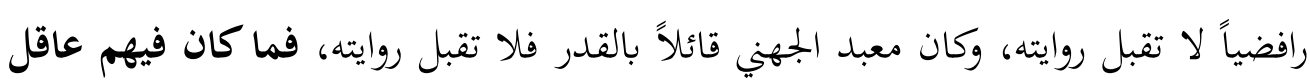

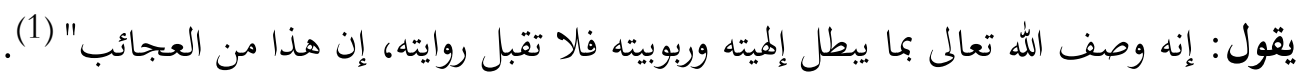
وهذا كلام باطل شنيع، تغني حكايته عن رده. 